\title{
Welding diagnostics by means of line-to-continuum method and SFFS spectral band selection
}

\author{
J. Mirapeix*, P.B. García-Allende, A. Cobo, O. M. Conde, M. Lomer, J.M. Lopez-Higuera \\ Photonics Engineering Group, University of Cantabria, Ed. I+D Teleco, Av. Los Castros s/n, 39005, \\ Santander (Spain)
}

\begin{abstract}
Plasma optical spectroscopy is a technique widely used for on-line welding diagnostics, given the rich information to be found within the plasma spectra generated during the process. One of the key factors in this regard is the computational performance of the whole monitoring system, as it determines the resulting spatial resolution. The electronic temperature of the welding plasma is typically used as the output monitoring parameter, but it requires an identification of the emission lines, what implies additional processing stages. In this paper we propose the use of the line-to-continuum method to generate the system output profiles, previously choosing the required spectral band by means of the SFFS algorithm.
\end{abstract}

Keywords: plasma spectroscopy, arc-welding, feature selection, quality monitoring

\section{INTRODUCTION}

Plasma optical spectroscopy is one of the most active areas of research in the field of on-line welding monitoring, as the optical radiation of the welding plasma generated during arc and laser welding can be acquired by means of an optical sensor system, and then processed to produce monitoring parameters exhibiting a direct correlation to the quality events of the associated seams [1,2]. The plasma electronic temperature $T_{e}$ is known to present this correlation, and has been widely employed in the literature $[3,4,5]$. Although a simplified expression using only two plasma emission lines is commonly selected for on-line analysis, new processing approaches are being proposed to find an optimal solution in terms of defect detection, but also considering their computational performance [6]. This parameter determines the temporal, and consequently spatial, resolution of the overall system, and it is critical for laser welding, where process speeds are typically much higher.

Alternatives to the so-called traditional spectroscopic approach has already been presented, being some of them based on completely new techniques, like correlation analysis [7], or synthetic spectrum generation and optimization algorithms [8]; and some others in solutions that can be considered within the framework of the classic spectroscopic analysis [9]. In this regard, we propose in this paper the use of a combination of these two different alternatives. On the one hand, we have designed an initial stage, to be performed off-line and with the information of tests performed on welding coupons, for example, where a spectral band selection is performed by means of the SFFS (Sequential Forward Floating Selection) algorithm; thus obtaining the most significant spectral bands in terms of defect discrimination. On the other hand, a classical method for plasma diagnostics, the line-to-continuum method, that has not been used for welding diagnostics, has been chosen to generate the output monitoring parameter.

\section{SPECTRAL BAND SELECTION AND LINE-TO-CONTINUUM METHOD}

\subsection{Spectral band selection by means of SFFS}

SFFS is a feature selection algorithm based on class separability [10]. Basically, SFFS assumes that there are several classes (or statistical distributions) to be discriminated, being in this case the data to be processed the welding spectra. In this regard, feature means therefore each one of the spectral bands where the spectrum is measured. The final aim of SFFS is to choose $M$ out of the $N$ original spectral bands, where $M<N$, and $M$ should be those spectral bands that best

*mirapeixjm@unican.com; phone +34942200877; http://gif.teisa.unican.es

20th International Conference on Optical Fibre Sensors, edited by Julian Jones, Brian Culshaw, Wolfgang Ecke, José Miguel López-Higuera, Reinhardt Willsch, Proc. of SPIE Vol. 7503, 75034T (c) 2009 SPIE · CCC code: 0277-786X/09/\$18 · doi: 10.1117/12.834914 
discriminate among the classes considered. It is worth mentioning that SFFS has already been considered in some works by our group for on-line welding monitoring [11], but in this cases SFFS was used to provide a set of spectral bands feeding an Artificial Neural Network (ANN). In this work, two different experimental welding tests have been considered in this initial stage. After the correlation analysis, where those spectral bands without correlation to each other are selected, SFFS offers a list with the spectral bands sorted in terms of their relevance for discrimination among classes. In our particular scenario, two different classes have been defined: correct seam and defect. With a set of different flaws defect discrimination could be feasible, but in this preliminary study we have decided to distinguish just between correct welds and defects.

The 23 spectral bands obtained with SFFS are also listed in Table 1, where Cont. means that for the selected spectral band there is no emission line but continuum, and * denotes that the spectral band is not centered at a particular emission line, but it is affected by its changes (i.e. it is in the vicinity of that line).

\subsection{Line-to-continuum method}

As previously commented, $T_{e}$ has been the traditional spectroscopic parameter used to generate the profiles where strong perturbations help to identify the appearance of defects. However this approach, although perfectly feasible for on-line analysis, could be improved for those applications requiring high welding speeds, for example. The line-to-continuum method allows to determine $T_{e}$ by only using a single emission line that, in addition, does not need to be identified. This method has not been used, to our knowledge, in this framework, and we have initially checked its suitability in [9]. The problems related to the ambiguity in the emission line selection can be avoided by the technique proposed in this paper, where SFFS is used to choose those lines that best discriminate among defects. It is worth mentioning that, although there is an expression allowing to estimate $T_{e}$ with this solution [9], we will only use the ratio between the line intensity and its associated continuum signal as the output monitoring parameter.

Table. 1. Spectral bands selected and listed by SFFS and related to species participating in the plasma.

\begin{tabular}{|c|c|c|c|c|c|}
\hline Spectral band (nm): order & Species & Spectral band (nm): order & Species & Spectral band (nm): order & Species \\
\hline 375.03: (1) & Cont. & 357.93: (9) & Cr I & 393.04: (17) & $\mathrm{CrI} *$ \\
\hline 518.41: (2) & Cr I & 396.48: (10) & Cr I & 488.14: (18) & Ar II * \\
\hline 392.87: (3) & $\mathrm{Fe} \mathrm{I}$ & 403.33: (11) & Mn I & 382.00: (19 & Fe I \\
\hline 481.08: (4) & $\mathrm{Mn} \mathrm{I} *$ & 396.64: (12) & $\mathrm{Cr} \mathrm{I}$ & 355.74: (20) & Ni I \\
\hline 434.75: (5) & $\mathrm{Cr} \mathrm{I}$ & 435.70: (13) & $\mathrm{CrI} *$ & 357.09: (21) & NI I * \\
\hline 480.62: (6) & Ar II & 439.95: (14) & $\mathrm{Fe} \mathrm{I}$ & 423.00: (22) & Ar II * \\
\hline 487.84: (7) & Ar II & 397.13: (15) & $\mathrm{Cr} \mathrm{I} *$ & $356.75:(23)$ & Ni I \\
\hline 360.63: (8) & $\mathrm{Cr} \mathrm{I}$ & 357.26: (16) & $\mathrm{Cr} \mathrm{I} *$ & & \\
\hline
\end{tabular}

\section{EXPERIMENTAL RESULTS}

The two experimental tests considered in our studies were bead-on-plate TIG-welding seams performed on AISI-304 stainless steel plates. The experimental setup was formed by a TIG power source and torch, a high-precision positioning system and a $2 \mathrm{~m}$ optical fiber ( $50 \mu \mathrm{m}$ core diameter) attached to an Ocean Optics USB2000 CCD-spectrometer (spectral range from 195 to $535 \mathrm{~nm}$, approximately). Argon was used as shielding gas with a constant flow rate of $12 \mathrm{~L} / \mathrm{min}$. The defects on the seams were caused by a perturbation in this flow, manually performing a shortening to $2 \mathrm{~L} / \mathrm{min}$ during approximately $0.5 \mathrm{~s}$. This action provoked the discontinuities in the seams highlighted in Fig. 1(a) (seam $\left.n^{\circ} 1\right)$ and (b) $\left(\operatorname{seam} n^{\circ} 2\right)$.

Fig. 1(c) and (d) show the results of the line to continuum method (where $I_{L}$ is the line intensity and $I c$ the one associated to the continuum) for the first spectral band provided by SFFS, located at $375.03 \mathrm{~nm}$. As described in Table 1, this band does not correspond to any specific emission line. The resulting profiles indicate subtle perturbations for the defective 
section of seam $n^{\circ} 1$ at $\mathrm{x} \approx 6 \mathrm{~s}$, and seam $n^{\circ} 2$ at $\mathrm{x} \approx 7 \mathrm{~s}$. It can be also seen that the initial section of seam $n^{\circ} 1$ also shows a dip, corresponding to a lower welding current chosen at the beginning of the test $(20 \mathrm{~A}$, and $40 \mathrm{~A}$ for the rest of the process). Regarding seam $n^{\circ} 2$, the first defect at $\mathrm{x} \approx 4.5 \mathrm{~s}$ can not be clearly distinguished in Fig. 2(d). The results depicted in Fig. 1(e) and (f) have been obtained considering the spectral band located at $481.08 \mathrm{~nm}$. In this case the profiles exhibit an improved sensitivity to the quality of the seams. In fact, the lack of penetration at the beginning of seam $n^{\circ} 2$, that was unintentionally generated by an excessive distance between the electrode tip and the plate, can be also identified in Fig. 1(f).

To illustrate the performed analysis a sample of the plasma spectra for correct and defective weld is presented in Fig. 2. In this example the variations of the spectral band located at $481.08 \mathrm{~nm}$ can be appreciated for both seams $n^{\circ} 1$ and $n^{\circ} 2$.

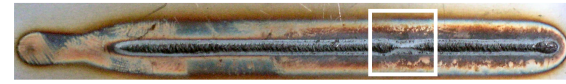

a)
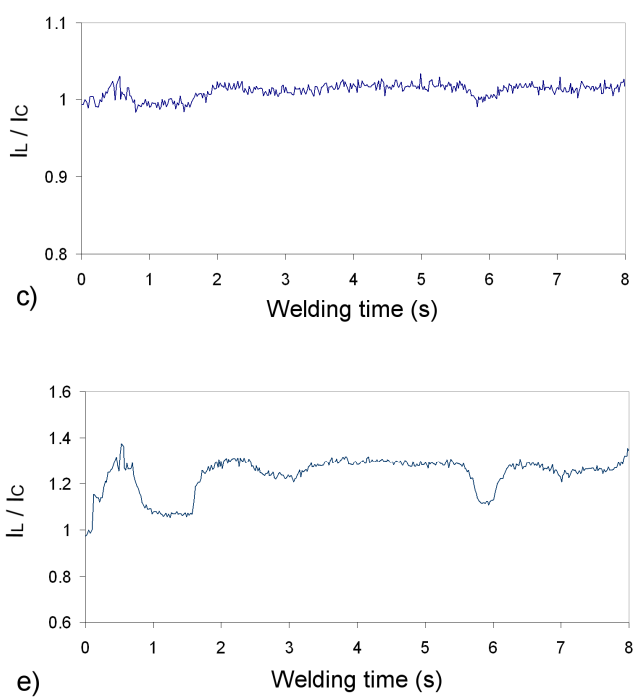

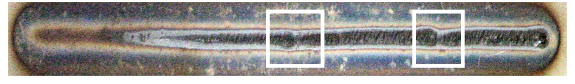

b)
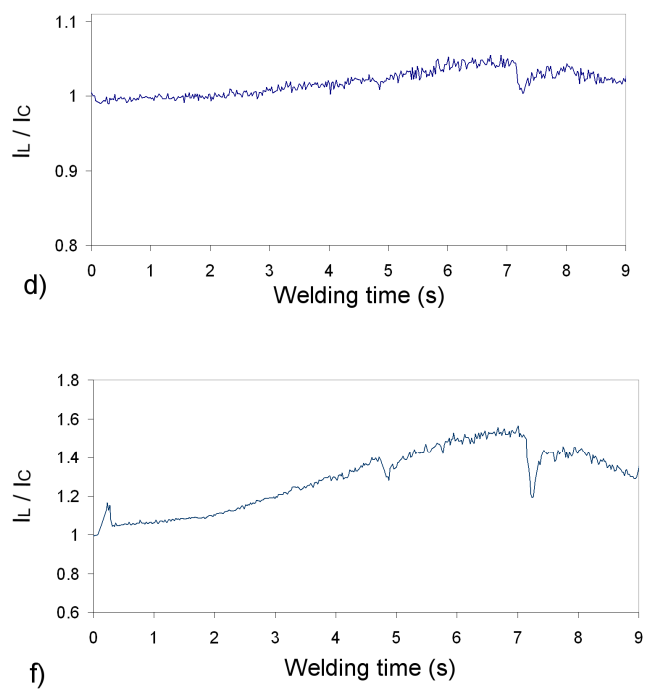

Fig. 1. Experimental welding tests on AISI-304: a) seam $\mathrm{n}^{\circ} 1$; b) seam $\mathrm{n}^{\circ} 2$; c) and d) $I_{L} / \mathrm{I}_{C}$ profiles with $375.03 \mathrm{~nm}$ for seam $\mathrm{n}^{\circ} 1$ and 2 , respectively; ; e) and f) $I_{L} / I_{C}$ profiles with $481.08 \mathrm{~nm}$ for seam $\mathrm{n}^{\circ} 1$ and 2 , respectively.

$$
\text { — Correct } \quad \text { Seam Defect }
$$

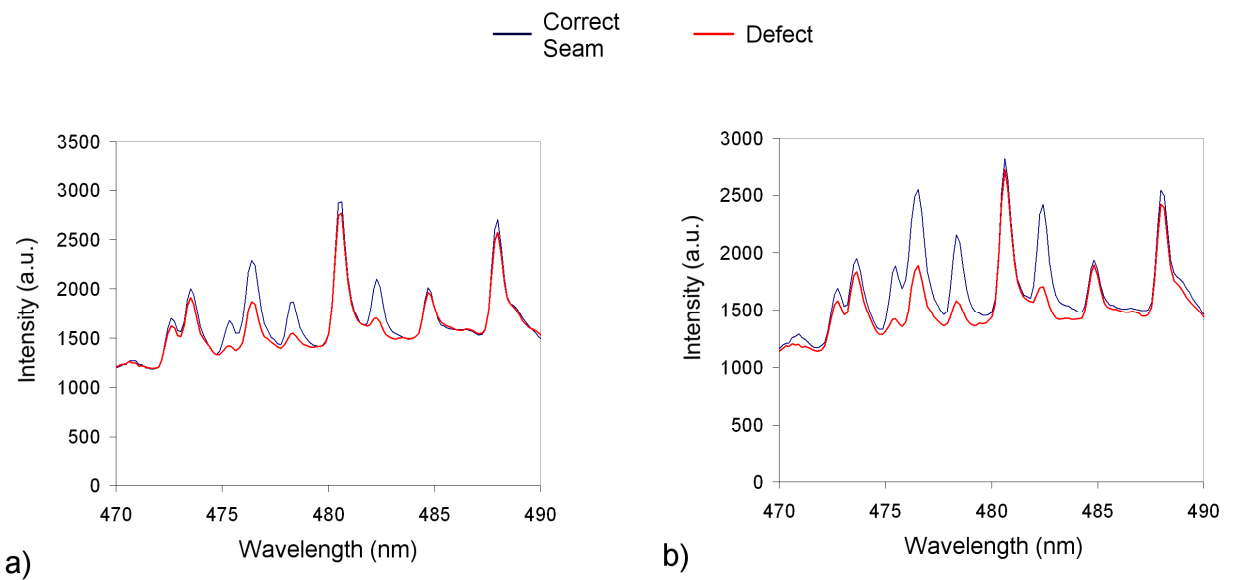

a)

Fig. 2. Comparison between plasma spectra for correct and defective seam: a) seam $n^{\mathrm{o}} 1$; b) seam $\mathrm{n}^{\mathrm{o}} 2$. 


\section{CONCLUSIONS}

In this paper we have investigated an alternative spectroscopic approach for on-line welding diagnostics based on feature selection and the line to continuum method. In an initial stage, the SFFS algorithm is used to obtain those spectral bands from the welding plasma spectra that best discriminate among correct welding and the appearance of defects. In a second stage we propose to employ the line to continuum method in those wavelengths chosen by SFFS to generate the required output parameter of the monitoring system. We have checked this proposal by means of TIG welding tests, verifying the feasibility of this solution for on-line analysis. Further studies will be conducted including an extended set of defects with different target materials.

\section{ACKNOWLEDGEMENTS}

This work has been co-supported by the project TEC2007-67987-C02-01. Authors also want to thank J.J. Valdiande for his valuable support during the experimental welding tests.

\section{REFERENCES}

[1] Farson, D.F. and Kim, K.R., "Generation of optical and acoustic emissions in laser weld plumes," Journal of Applied Physics, 85, 1329-36 (1999).

[2] Bardin F., Cobo A., López-Higuera J.M., Collin O., Aubry P., Dubois T., Hogstrom M., Nylen P., Jonsson P., Jones J.D.C. and Hand D.P., "Optical techniques for real-time penetration monitoring for laser welding," Applied Optics, 44, 3869-76 (2005).

[3] Sforza, P. and de Blasiis, D., "On-line optical monitoring system for arc welding," NDT E. Int., 35, 37-43 (2002).

[4] Sibillano, T., Ancona, A., Berardi, V., Schingaro, E., Parente, P. and Lugara, P.M., "Correlation spectroscopy as a tool for detecting losses of ligand elements in laser welding of aluminium alloys," Opt Lasers Eng, 44, 1324-35 (2006).

[5] Mirapeix J., Cobo A., Conde O.M., Jauregui C. and Lopez-Higuera J.M., "Real-time arc welding defect detection technique by means of plasma spectrum optical analysis," NDT\&E International, 39, 356-60 (2006).

[6] Mirapeix, J., Cobo, A., Jauregui, C. and Lopez-Higuera, J.M. "Fast algorithm for spectral processing with application to on-line welding quality assurance," Meas. Sci. Technol., 17, 2623-2629 (2006).

[7] Sibillano, T., Ancona, A., Berardi, V., Schingaro, E., Parente, P. and Lugara, P.M., "Correlation spectroscopy as a tool for detecting losses of ligand elements in laser welding of aluminium alloys," Opt Lasers Eng, 44, 1324-35 (2006).

[8] Mirapeix, J., Cobo, A., Gonzalez, D.A. and Lopez-Higuera, J.M., "Plasma spectroscopy analysis technique based on optimization algorithms and spectral synthesis," Opt. Express, 15, 1884-97 (2007).

[9] Mirapeix, J., Cobo A., Fernandez S., Cardoso R. and Lopez-Higuera J.M., "Spectroscopic analysis of the plasma continuum radiation for on-line arc-welding defect detection," J Phys D, 41, 135202-10 (2008).

[10] Ferri, F., Pudil, P., Hatef, M. and Kittler, J., "Comparative study of techniques for large-scale feature selection," Pattern Recognition in Practice IV: Multiple Paradigms, Comparative Studies, and Hybrid Systems, 403-413 (1994).

[11] Garcia-Allende, P.B., Mirapeix, J., Conde, O.M., Cobo, A. and Lopez-Higuera, J.M., "Spectral processing technique based on feature selection and artificial neural networks for arc-welding quality monitoring," NDT\&E International, 42, 56-63 (2009). 